\title{
Supporting Information for: \\ A Compact All-Carbon Tripodal Tether Affords High Coverage of Porphyrins on Silicon Surfaces
}

Kisari Padmaja, Lingyun Wei, Jonathan S. Lindsey, and David F. Bocian

\section{Table of Contents}

General Experimental Section

$\mathrm{S} 1$

Spectral data

S2-S10

General. ${ }^{1} \mathrm{H}(400 \mathrm{MHz})$ and ${ }^{13} \mathrm{C}(100 \mathrm{MHz})$ NMR spectra were recorded in $\mathrm{CDCl}_{3}$ unless noted otherwise. IR spectra were recorded in $\mathrm{CH}_{2} \mathrm{Cl}_{2}$. Absorption spectra were collected in toluene. Porphyrin complexes were analyzed by FABMS and laser desorption mass spectrometry in the absence of a matrix (LDMS), or by MALDI-MS using 1,4-bis(5-phenyloxazol-2-yl)benzene (POPOP) as the matrix. Silica gel (40 $\mu \mathrm{m}$ average particle size) was used for column chromatography. Commercial samples of allyl magnesium chloride (2 M solution in THF), DIBAL-H (1 M solution in hexanes), and 4-(trifluoromethyl)aniline were used as received. THF was freshly distilled from $\mathrm{Na} /$ benzophenone. 


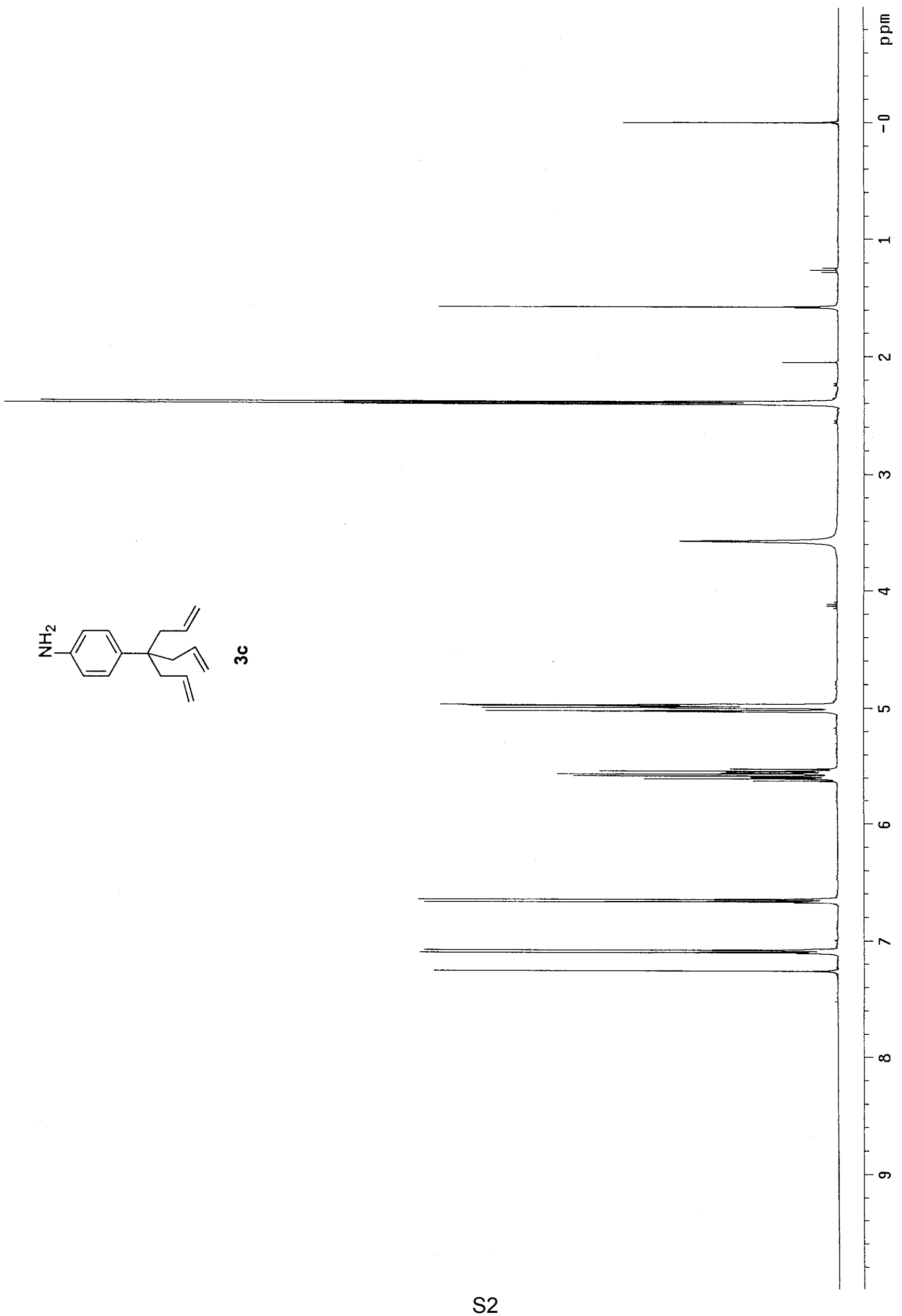




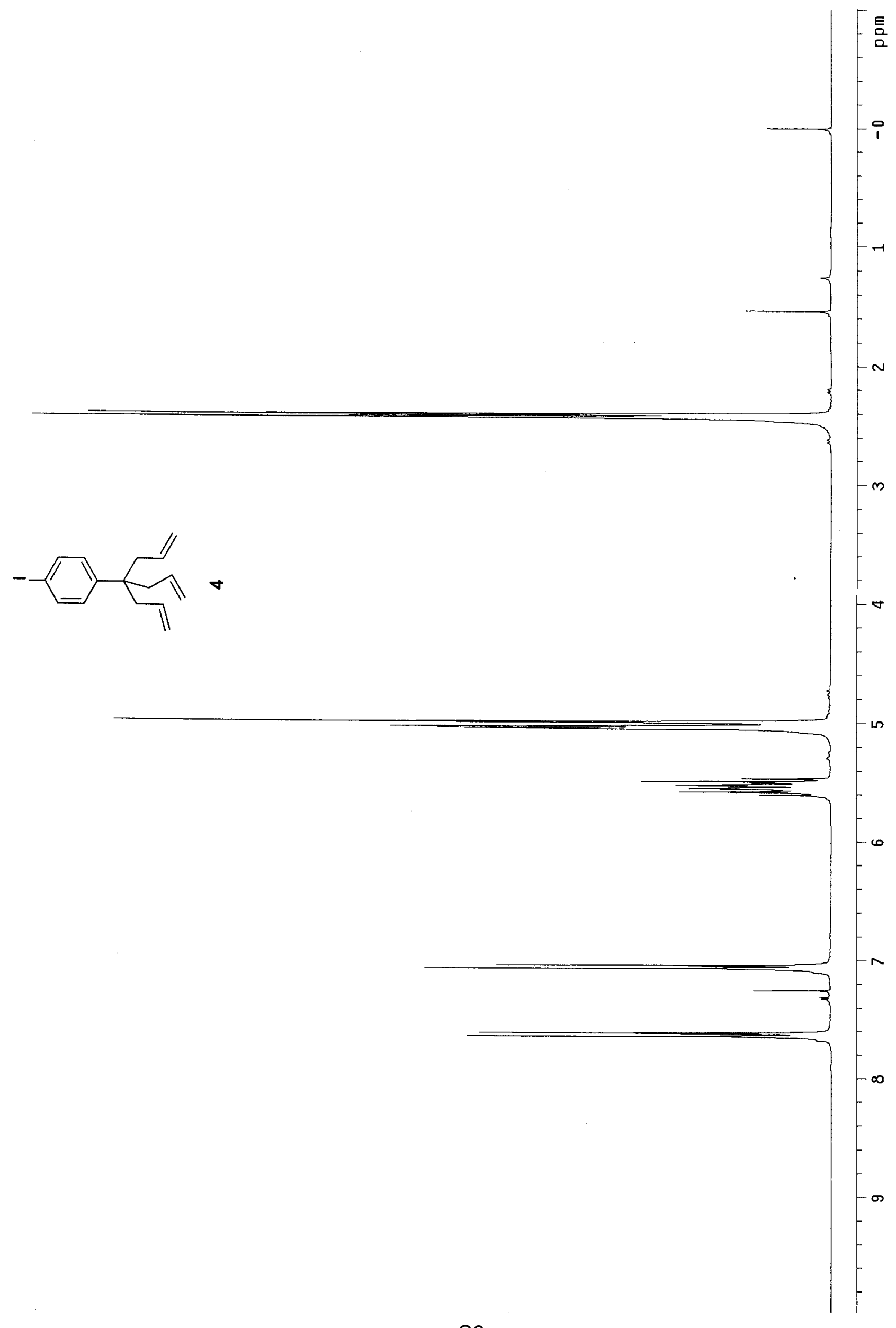




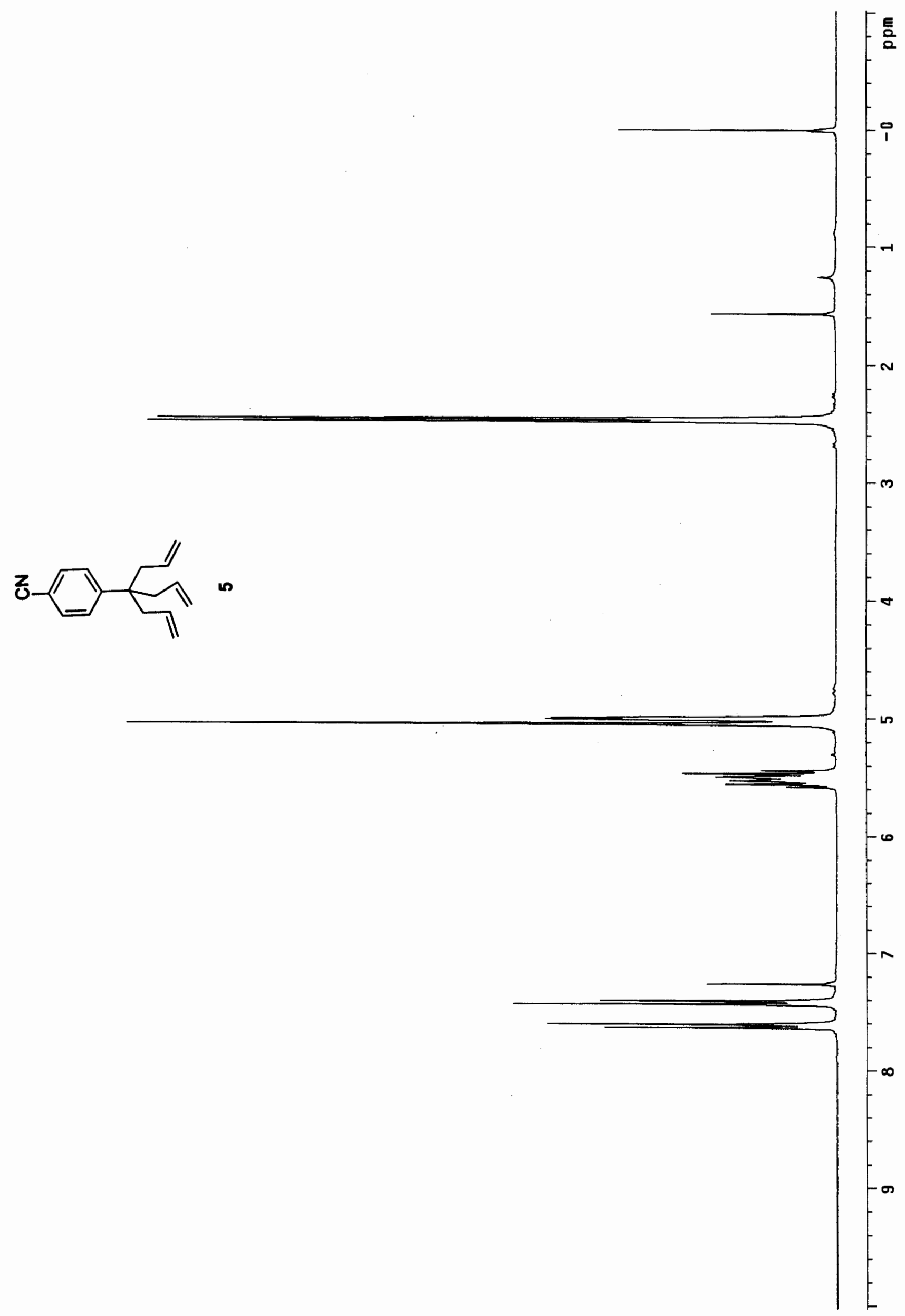




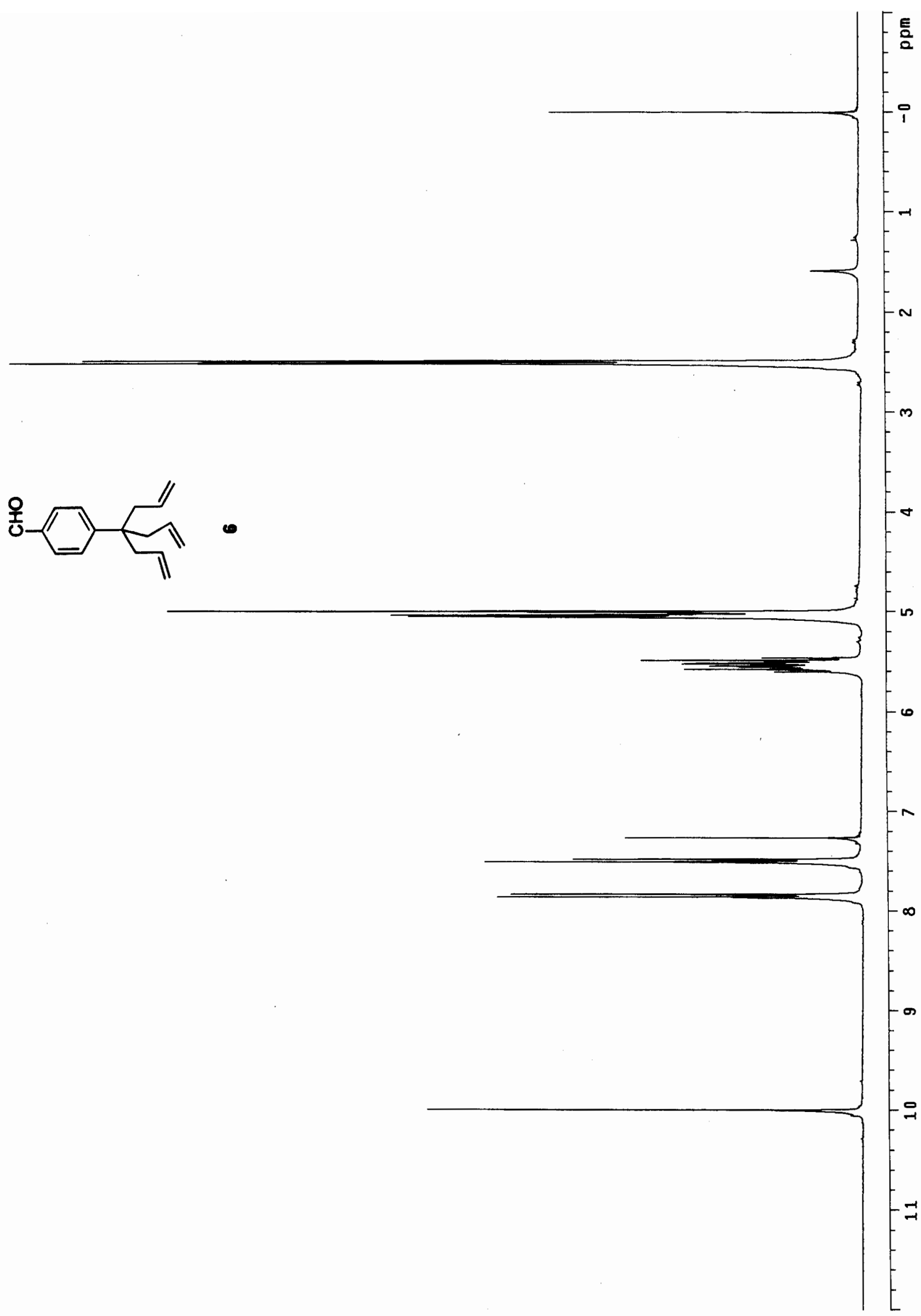




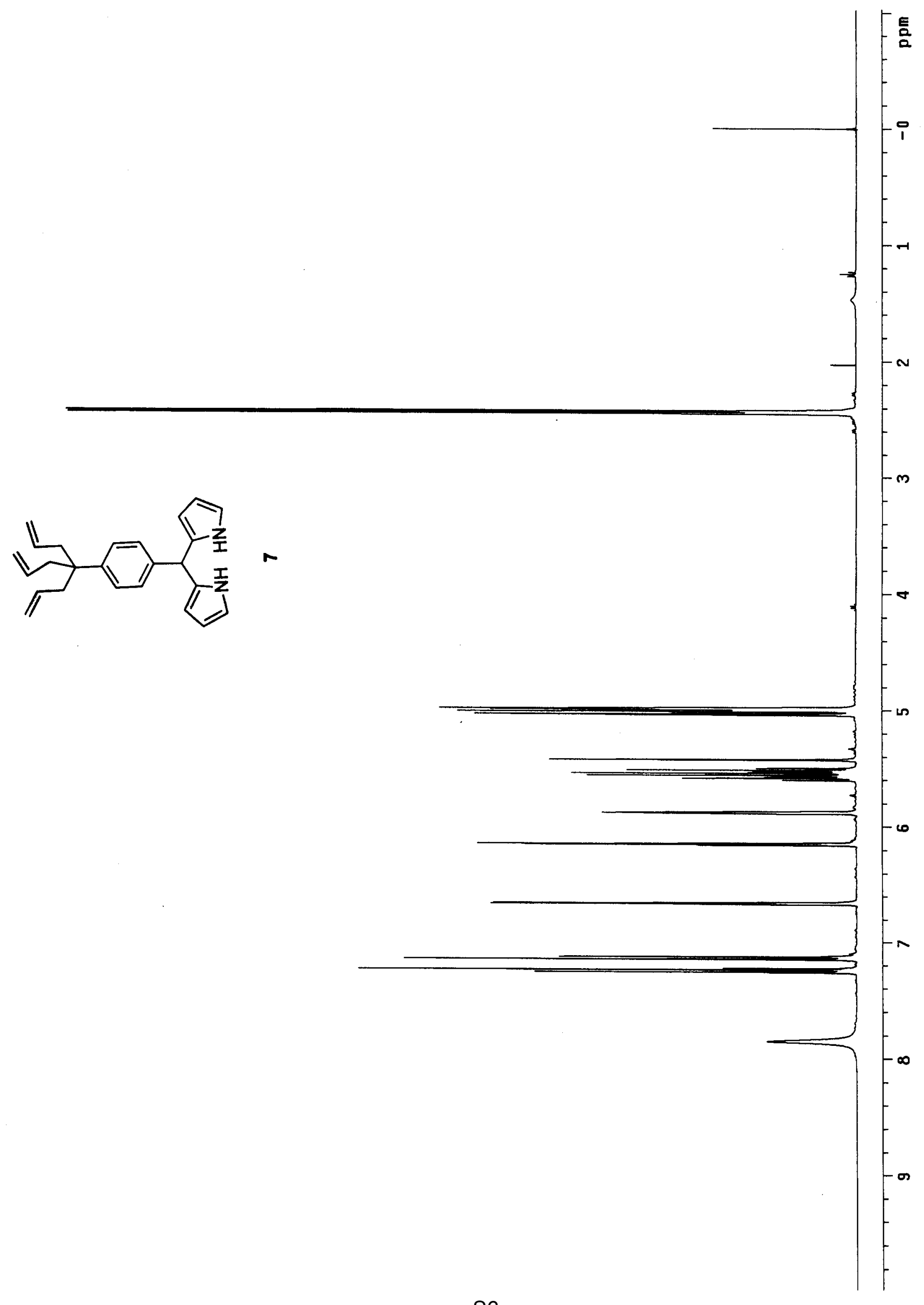




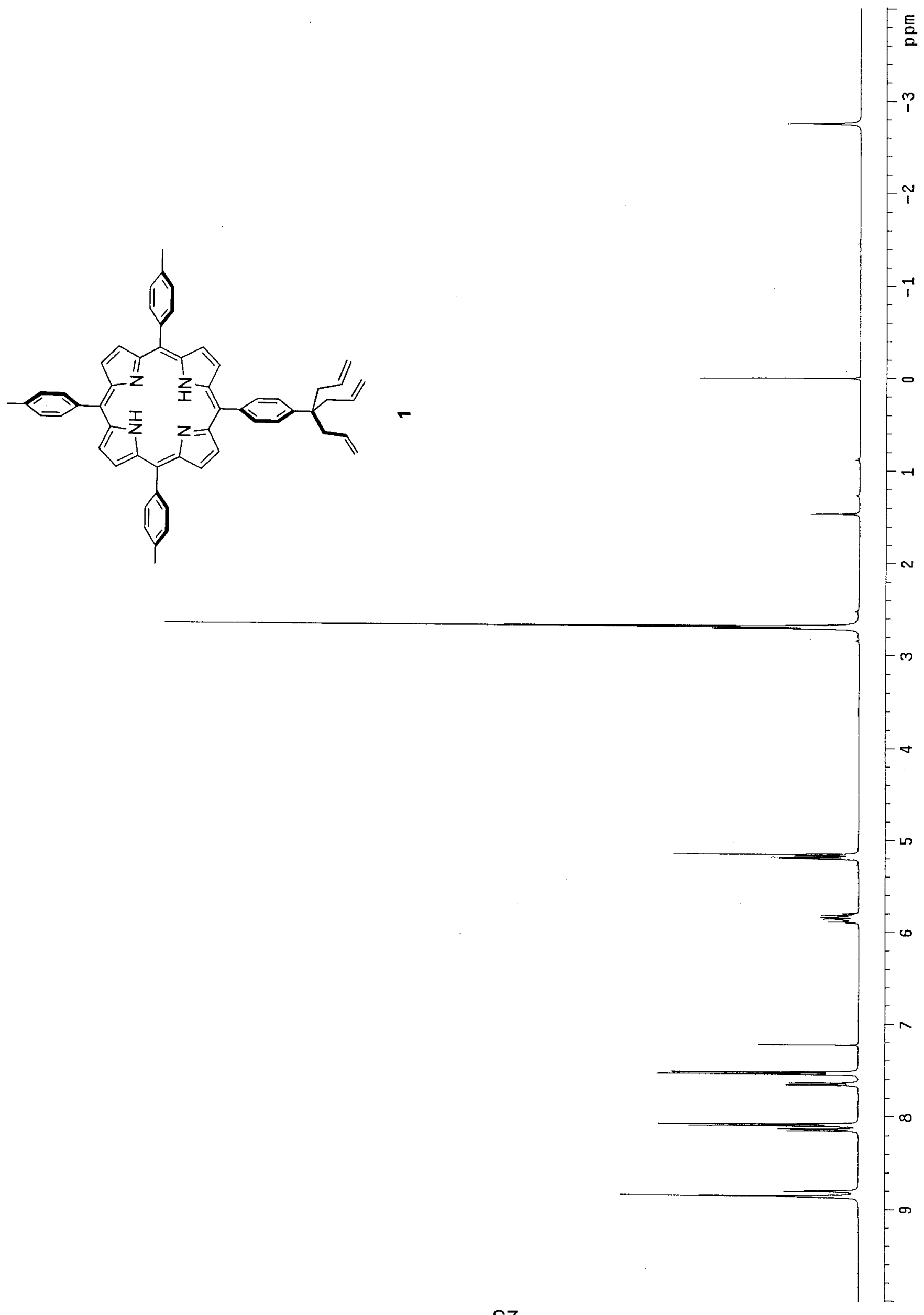




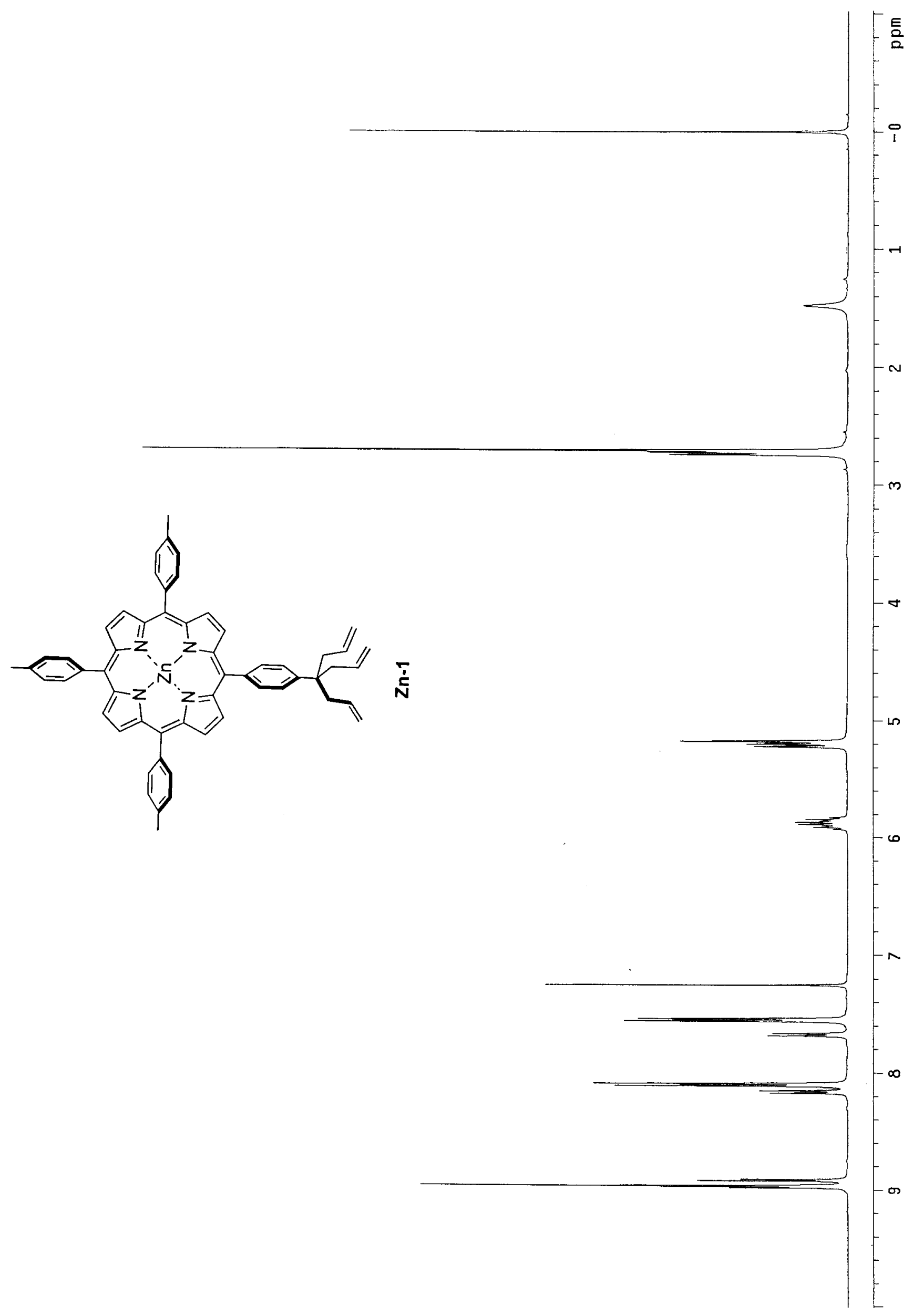




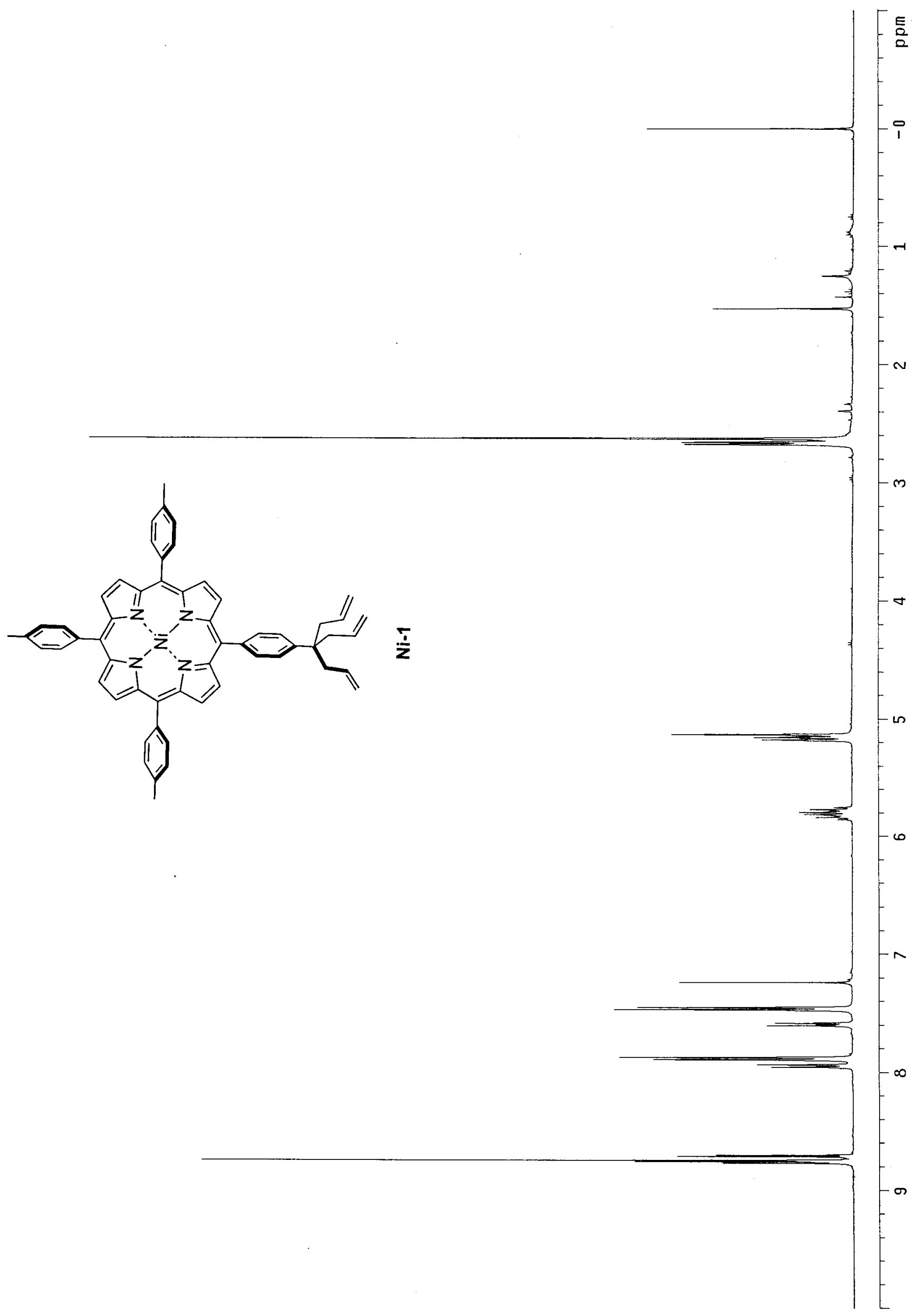




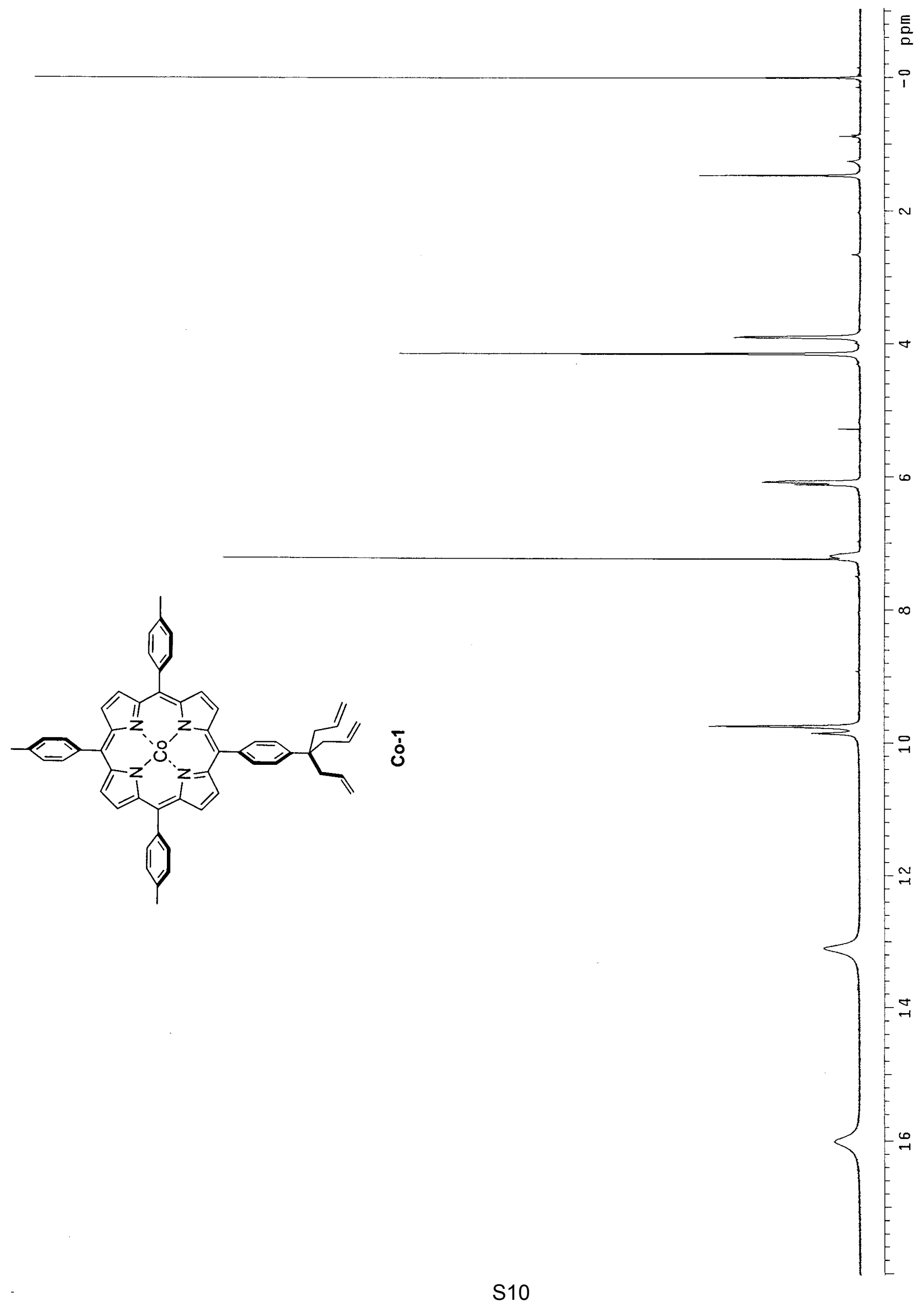

